NISTIR 7913

\title{
Review on Sustainability Characterization for Manufacturing Processes
}

\author{
Mahesh Mani \\ Jatinder Madan \\ Jae Hyun Lee \\ Kevin W. Lyons \\ Satyandra K. Gupta
}

http://dx.doi.org/10.6028/NIST.IR.7913 
NISTIR 7913

\title{
Review on Sustainability Characterization for Manufacturing Processes
}

\author{
Mahesh Mani \\ Jatinder Madan \\ Jae Hyun Lee \\ Kevin W. Lyons \\ Systems Integration Division \\ Engineering Laboratory \\ Satyandra K. Gupta \\ Department of Mechanical Engineering \\ University of Maryland
}

http://dx.doi.org/10.6028/NIST.IR.7913

February 2013

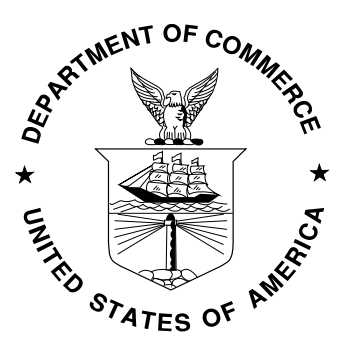

U.S. Department of Commerce Rebecca Blank, Acting Secretary

National Institute of Standards and Technology Patrick D. Gallagher, Under Secretary of Commerce for Standards and Technology and Director 


\section{Table of Contents}

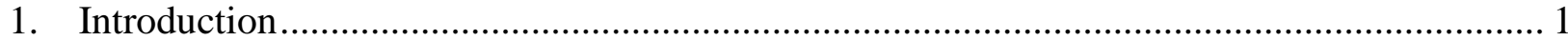

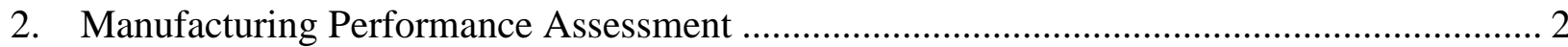

2.1. Process Characterization vs. Performance Measurement .................................................. 2

2.2. Challenges in Developing the Measurement Science........................................................ 3

3. Background Review................................................................................................. 4

3.1. Manufacturing Process Taxanomy ………………………………………………......... 4

3.1.1. Unit manufacturing process research committee report ........................................... 4

3.1.2. Todd et al. manufacturing taxonomy ……………................................................. 5

3.1.3. DIN 8580 classification .................................................................................. 5

3.1.4. Ashby's taxonomy ………………………….................................................. 6

3.1.5. Manufacturing management taxonomy …………................................................... 7

3.1.6. Industry level classifications.............................................................................. 7

3.2. Indicators for Sustainable Manufacturing................................................................... 7

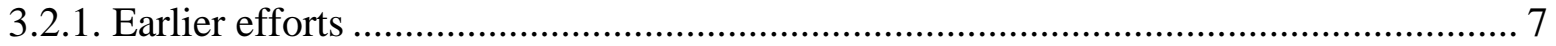

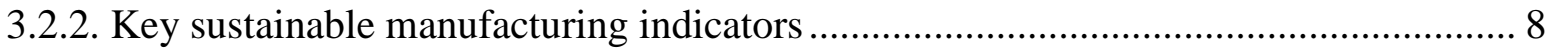

3.3. Manufacturing Process Models ............................................................................. 10

3.3.1. Classification of process models....................................................................... 10

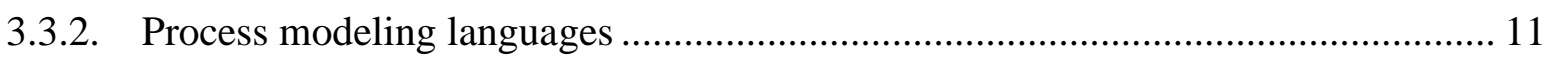

3.3.3. Manufacturing process - activity models ............................................................ 12

3.3.4. Manufacturing process - information models ................................................. 13

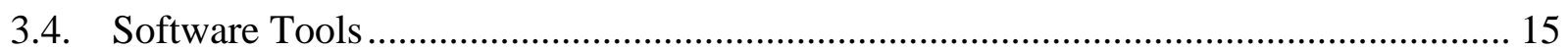

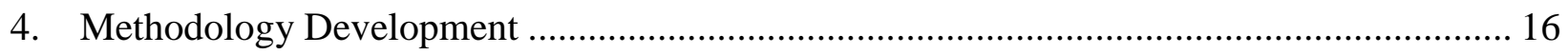

4.1. Sustainability Characterization Methodology ……………………………………..... 17

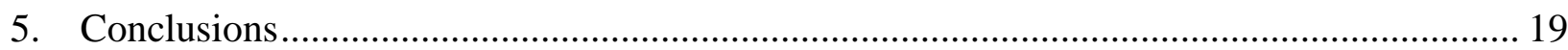

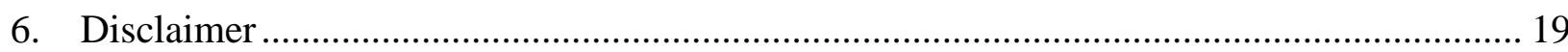

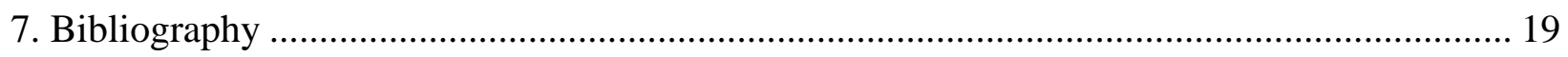




\begin{abstract}
Manufacturing industries lack the measurement science and the needed information base to measure and effectively compare environmental performances of manufacturing processes, resources and associated services with respect to sustainability. The current use of ad-hoc methods and tools to assess and describe sustainability of manufactured products does not necessarily account for manufacturing processes explicitly, and hence results in inaccurate and ambiguous comparisons. Further, we identified that there are no formal methods for acquiring and exchanging information that help establish a consolidated sustainability information base. Our ultimate goal is to develop the needed measurement science and methodology to evaluate sustainability of fundamental manufacturing processes to ensure reliable and consistent comparisons. As a precursor, this report presents a background review on related work to evaluate sustainability performance. We discuss identified manufacturing process classifications, sustainable manufacturing indicators and computable metrics, relevant information models, and software tools. An overview of future research is also presented.
\end{abstract}

Keywords: sustainability characterization, performance measurement, unit manufacturing processes, key performance indicators, measurement science, knowledge management

\title{
1. Introduction
}

Sustainable manufacturing is defined as the creation of manufactured products that use processes that minimize negative environmental impacts, conserve energy and natural resources, are safe for employees, communities, and consumers and are economically sound [1]. According to the National Association of Manufacturers, the industrial sector accounts for $31 \%$ of all the energy consumed in the United States. Manufacturing alone accounts for $65 \%$ of the industrial sector's energy consumption [2]. With manufacturers looking to diversify their energy supplies and improve their energy efficiency due to an increasing energy price tag, a model for sustainable manufacturing among industries has become important.

Manufacturing processes and their corresponding resources are developed to support the production of end-user products. Ultimately, the focus is on meeting customer needs, besides being sustainable. Further, to enforce compliance, it is expected that manufacturing industries today pay emission taxes [3]. Sustainability related performance measurement of manufacturing processes has hence become a crucial effort.

Performance measurement, in general, identifies the gaps between the current and desired performance, and provides an indication of the progress made towards closing the gaps. Related performance indicators compress large amounts of information into a format that is easier to understand, compare and manipulate. Companies often use such indicators to set targets and monitor their consequent success. Traditionally, manufacturing related performance indicators provided information on the productivity and included throughput, cost, quality, material, etc.

Performance measurement of sustainable manufacturing should not only include a performance indicator but the metric for that indicator also. The challenge, however, is in identifying the sustainability performance indicators that directly relate to manufacturing metrics, e.g. energy utilization versus productivity. A number of indicators have been proposed in the past for sustainability performance measurement [4]. From this exhaustive list of sustainability performance indicators, some are commonly used in the industry, and are also known as key performance indicators (KPIs). These KPIs are used to evaluate the success of a particular activity with respect to sustainability [5]. For instance, one of the commonly used performance indicator for injection molding process is energy per unit of mass and the corresponding metric is $\mathrm{kWh}$ per $\mathrm{kg}$ (or MJ per kg) of injection molded parts.

To remain globally competitive, manufacturers must increase the flexibility, speed of production systems and their supplier networks, while also reducing environmental impacts and energy requirements [6]. These changes require a transformation from manufacturing practices based on experience and best practices towards science-based modeling, decision making, and production. This review report presents 
a state of the art study on manufacturing process characterization, fundamental measurements, standards, and tools to enable U.S. manufacturers to make this transformation. The motivation of this report is to facilitate the development of the measurement science and methodologies, performance indicators and metrics and, related information models for fundamental manufacturing processes to evaluate sustainability.

The report is organized as follows. Section 2 presents how process characterization is an inherent part of performance measurement. This section also outlines the challenges in developing the required measurement science for sustainability of manufacturing processes. Section 3 presents a background review on the different manufacturing process classifications, sustainability indicators, process information models followed by a brief review of the relevant software tools for sustainability. Section 4 presents the methodology development for sustainability characterization for manufacturing processes. Section 5 presents our proposed scope of work towards sustainability characterization followed by conclusions.

\section{Manufacturing Performance Assessment}

In this section, we first outline how process characterization is an inherent part of performance measurement and discuss how process characterization can be used for developing the science-based performance measurement for sustainability. Next, we briefly present the challenges in developing the required measurement science followed by the relevant research efforts made towards development of methodologies for performance measurement for sustainability. Finally, we conclude the section summarizing the benefits associated with the development of science based performance measurement methodologies for sustainable manufacturing.

\subsection{Process Characterization vs. Performance Measurement}

A process characterization activity typically identifies key inputs and outputs of a process, collects data over the entire operating range, estimates the steady-state behavior at optimal operating conditions and builds models describing the parametric relationships across the operating range. The result of process characterization activity is a set of mathematical process models that can be used to monitor and improve the process [7]. Figure 1 [8] shows an instance of a process as a system boundary along with possible inputs and outputs.

Manufacturing process characterization can be useful when: bringing a new process or tool into use, bringing a tool or process back up after scheduled/unscheduled maintenance, compare tools or processes, check the health of our process during the monitoring phase, troubleshooting a bad process, or in our case, to determine the sustainability performance.

Performance measurement is complementary to process characterization, with feedback control for improved results. We are of the opinion that production process characterization [7] can be used as a promising methodology for sustainable manufacturing; the challenge however is in developing the measurement science. 


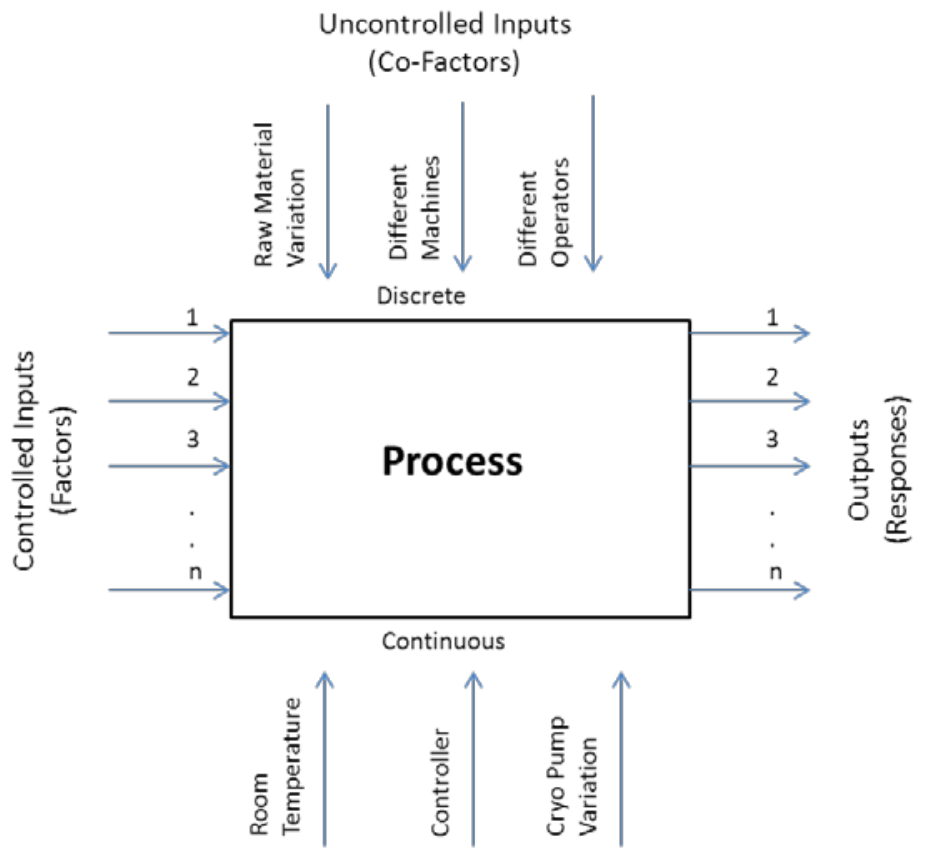

Figure 1 Boundaries of a process under study

\subsection{Challenges in Developing the Measurement Science}

The major obstacle in developing absolute measures for sustainability is the absence of a well-defined approach to characterize sustainability for manufacturing. Characterizing sustainability will help manufacturing industries to improve productivity through ways of improvement in process control by way of better resource management. Different manufacturing processes and resources have different or overlapping capabilities with varying efficiencies. It is well understood that the currently available LCA (Life Cycle Assessment) tools [9,10] use LCI (Life Cycle Inventory) databases, which are typically limited to primary material production only (e.g. sheets, foils, etc.) and recycling processes [11]. General approximations made today for sustainability ignores the manufacturing process related LCI and hence result in inaccurate planning for cross comparisons and decision making.

Developing the measurement science for sustainability at various system levels (e.g. resources vs. facility, facility vs. factory, and factory vs. supply chain) can help manufacturing industries for enhanced manufacturing resource management.

Following are the challenges to develop the measurement science:

- uncertainties in manufacturing environment

- dramatic changes in customer requirements

- innovation in production technology

- uncertainties in internal operating environment

- inadequate traditional approach to overcome uncertainties

- inadequate and unstructured information

- inadequate decision models

- $\quad$ undefined scope and boundaries within manufacturing unit processes

- multiple unverified proposed measurement methodologies 
Note that sustainability, like quality, is in the eyes of the beholder. The meaning of sustainability varies, depending on the sector, category and region. Sustainability performance measurement for a manufacturing process can be used as a means of representing an aspect of quality. One analogy is the way impact factor of journal citations has become an accepted standard of quality. For sustainable manufacturing, a similar metric that delivers the impact and caters to an unbiased comparison is lacking. We propose to develop a science-based performance measurement for sustainable manufacturing building upon the traditional production process characterization methods [7].

\section{Background Review}

In this section we report and discuss on the related work towards developing the measurement science for sustainable manufacturing. We first review relevant classifications or taxonomies ${ }^{i}$ of manufacturing processes to understand their similarities and differences. Next, we briefly discuss the sustainability indicators with an emphasis on the key sustainability indicators for manufacturing. Then, we provide an overview of the relevant manufacturing process information models in the context of sustainable manufacturing. Finally in this section, we present selected software tools that aid in computing sustainability and their shortcomings.

\section{1. $\quad$ Manufacturing Process Taxonomy}

Manufacturing processes involve the conversion of raw materials into finished products with specific shape, structure, and properties to fulfill certain requirements [8]. This conversion into finished products is accomplished using a variety of manufacturing processes that utilize energy to produce controlled changes in the configuration properties of materials. The energy applied during processing may be mechanical, thermal, electrical, or chemical in nature. The results are meant to satisfy functional requirements that were defined during the product design stage. With growing concerns towards sustainability, and sustainable manufacturing in particular, these individual manufacturing processes must be meticulously characterized for performance efficiency. A manufacturing process taxonomy, i.e., welldefined manufacturing process classification, helps one to understand the different processes to identify ways to manufacture different products, understand associated process accuracy, competitive and relative process capabilities and most importantly get all of the right information to make a decision. The classification should also provide the depth of information depending on the choice of manufacturing process. The following are selected taxonomy/classifications of manufacturing processes available in the literature.

\subsubsection{Unit manufacturing process research committee report}

The Unit Manufacturing Process Research Committee, Commission on Engineering and Technical Systems, National Research Council (NRC) identifies unit processes as the individual steps required to produce finished goods by transforming raw material and adding value to the work piece as it becomes a finished product [8]. The information and material flow associated with a typical unit process is shown in Figure 2. Raw material or parts from a previous unit process are inputs. The output consists of parts, which are one step closer to their final form, and of an influence on the environment, such as particulate or noise pollution. The information input and control to the unit process include product data, process information, and process control methodology. The resource requirements of the unit process are such items as manufacturing equipment, energy, and human resources. 


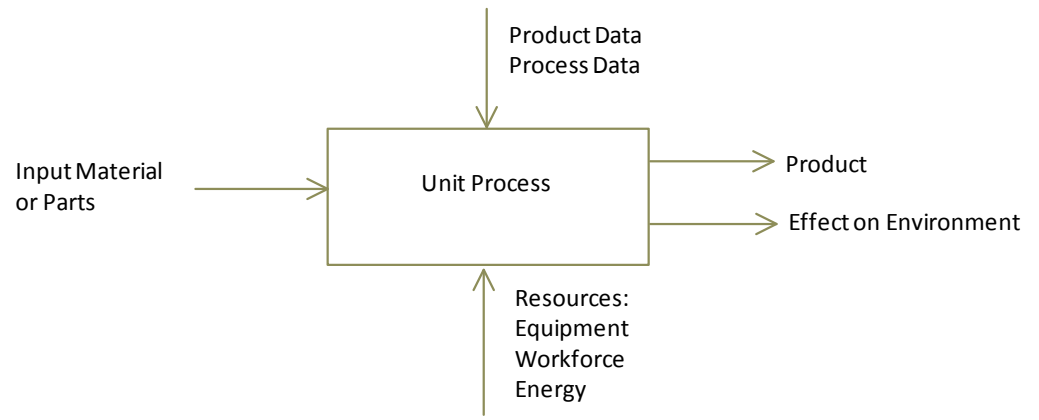

Figure 2 Unit process information and input materials flow representation

The NRC report [8] considers a unit process to be optimized when the value added in terms of the required configuration and property changes are delivered to the work-piece in the most cost-effective manner from the system as a whole. This involves minimization of factors such as energy use, scrap generation, labor costs, and capital equipment requirements. According to NRC, unit manufacturing processes are classified into five families of physical processes:

- Mass-change processes involve material removed or added by mechanical, electrical, or chemical means. These include plating, machining, grinding, as well as nontraditional removal processes such as electro-discharge and electro-chemical machining.

- Phase-change processes involve producing a solid part from material originally in the liquid or vapor phase. These include casting of metals, infiltration of composites, and injection molding of polymers.

- Structure-change processes involve altering the microstructure of a work-piece, either throughout its bulk or in a localized area, such as its surface. These include heat treatment and surface hardening processes.

- Deformation processes involve altering the shape of a solid work-piece without changing its mass or composition. These include processes of rolling and forging, and sheet-forming processes of deep drawing and ironing.

- Consolidation processes involve combining materials such as particles, filaments, or solid sections to form a part or component. These involve powder metallurgy, ceramic molding, and polymer-matrix composite pressing. Joining processes, such as welding and brazing, also belong to this process family.

\subsubsection{Todd et al. manufacturing taxonomy}

Six families of shaping processes that change the basic geometry of shape of a work piece (mass reducing, thermal mass reducing, chemical mass reducing, mass conserving, consolidation, and joining) and four families of non-shaping processes that modify the engineering and aesthetic properties of materials (hardening, softening, surface preparation, and surface coatings) are identified. This classification now used in the United States and Europe, is a valuable tool in identifying processes and their capabilities. Using the same classification system, detailed descriptions of each individual process can be found in the Manufacturing Processes Reference [12].

\subsubsection{DIN 8580 classification}

German standard, DIN 8580 [13] applies to a broad area of the manufacturing processes. It defines and explains basic concepts needed for the description and classification of manufacturing processes. Furthermore, in this standard the foundations for building a classification system are established. It classifies manufacturing processes in groups based on the criteria of: created from an initial form (original form), created from formless substance, the change in shape and material properties etc. Classification 
results in six main groups of the manufacturing processes as shown in Table 1. This standard is being used in the international cooperative effort on process emissions in manufacturing [14].

Table 1 Scope of the relevant manufacturing process classifications

\begin{tabular}{|c|c|c|c|c|c|c|}
\hline & \multicolumn{6}{|c|}{ Source } \\
\hline & NRC & Todd et al & DIN 8580 & Paul DeGarmo & Ashby & Mil \\
\hline 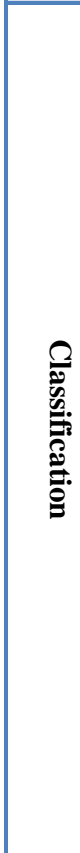 & $\begin{array}{l}\text { Five families of } \\
\text { physical } \\
\text { processes } \\
\text { - Mass-change } \\
\text { processes } \\
\text { - Phase-change } \\
\text { processes } \\
\text { - Structure- } \\
\text { change } \\
\text { processes } \\
\text { - Deformation } \\
\text { processes } \\
\text { - Consolidation } \\
\text { processes }\end{array}$ & $\begin{array}{l}\text { Six families of } \\
\text { Shaping } \\
\text { processes } \\
\text { - Mass } \\
\text { Reducing } \\
\text { - Thermal Mass } \\
\text { Reducing } \\
\text { - Chemical } \\
\text { Mass } \\
\text { Reducing } \\
\text { - Mass } \\
\text { Conserving } \\
\text { - Consolidation } \\
\text { - Joining } \\
\text { Four families of } \\
\text { Non-shaping } \\
\text { processes } \\
\text { - Hardening } \\
\text { - Softening } \\
\text { - Surface } \\
\text { Preparation } \\
\text { - Surface } \\
\text { Coatings }\end{array}$ & $\begin{array}{l}\text { Six groups of } \\
\text { manufacturing } \\
\text { processes } \\
\text { - Original } \\
\text { Forming } \\
\text { - Transforming } \\
\text { - Separating } \\
\text { - Joining } \\
\text { - Coating and } \\
\text { Finishing } \\
\text { - Change of } \\
\text { Material } \\
\text { Properties }\end{array}$ & $\begin{array}{l}\text { Seven types are } \\
\text { identified } \\
\text { - Casting or } \\
\text { Molding } \\
\text { - Forming or } \\
\text { Shearing } \\
\text { - Machining } \\
\text { (material } \\
\text { removal) } \\
\text { - Heat Treating } \\
\text { - Finishing } \\
\text { - Assembly } \\
\text { - Inspection }\end{array}$ & $\begin{array}{l}\text { Four groups of } \\
\text { manufacturing } \\
\text { processes } \\
\text { - Primary } \\
\text { shaping } \\
\text { processes: } \\
\text { - Secondary } \\
\text { processes: } \\
\text { - Joining } \\
\text { - Finishing }\end{array}$ & $\begin{array}{l}\text { Manufacturing } \\
\text { Management } \\
\text { Taxonomy } \\
\text { - Product } \\
\text { Design } \\
\text { - Process } \\
\text { Design\& } \\
\text { Control } \\
\text { - Supply Chain } \\
\text { Management }\end{array}$ \\
\hline 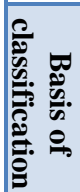 & Physical change & $\begin{array}{l}\text { Shaping/Non- } \\
\text { shaping }\end{array}$ & $\begin{array}{l}\text { Forming/ } \\
\text { Transforming/ } \\
\text { Material } \\
\text { Property }\end{array}$ & $\begin{array}{l}\text { Casting/Forming/ } \\
\text { Material Property }\end{array}$ & $\begin{array}{l}\text { Primary/ } \\
\text { Secondary }\end{array}$ & $\begin{array}{l}\text { Manufacturing } \\
\text { Management }\end{array}$ \\
\hline 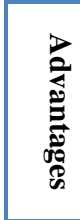 & Science-based & Ease of use & $\begin{array}{l}\text { Being used in } \\
\text { CO2PE! effort } \\
\text { for determining } \\
\text { LCI of } \\
\text { Manufacturing } \\
\text { Processes }\end{array}$ & Simple & Simple & Management \\
\hline
\end{tabular}

\subsubsection{Ashby's taxonomy}

Based on a survey of all standard processes (and not-so-standard) for materials manufacturing, Ashby proposes [15] four categories of manufacturing processes:

- Primary shaping processes: These include processes like casting, deformation (forging and rolling), powder processing (ceramics, nano-structured materials), and special methods like electro-forming and rapid prototyping.

- Secondary processes: Includes machining and heat treatment. They are secondary because they are used on something that's already been through some primary process.

- Joining: Includes welding, adhesive bonding, and fasteners.

- Finishing: Many of these are cosmetic, but also include performance improvement processes like polishing, coatings, etc. 


\subsubsection{Manufacturing management taxonomy}

In the Acquisition Community Connection [16], a manufacturing management taxonomy provides a flow down to identify, develop, capture and present various manufacturing knowledge objects within the manufacturing management special interest area [16]. Figure A1 in the Appendix presents the representative flow down.

\subsubsection{Industry level classifications}

Industry classifications based on the service are also available. For example in the mfg.com, the classification is based on supplier selection for manufacturing and outsourcing [17].

A background review of available manufacturing taxonomies enabled us to find pros and cons associated with each. Some classifications were at a high level and needed further breakdowns like the one defined by NRC. Todd \& Allen's taxonomy is a textbook popular classification, while DIN 8580 is a popular German classification. Some other classifications were catered more towards manufacturing management. However, the closest and most extensive were Todd et al.'s and the DIN 8580 taxonomy. Present international efforts for manufacturing process life cycle inventory primarily use the DIN 8580 [14] taxonomy, although co-operating institutions can also opt for Todd and Allen's taxonomy [12]. To achieve consistency with similar efforts, we plan to use Todd et al.'s and DIN 8580 taxonomy for sustainability process characterization purposes.

\subsection{Indicators for Sustainable Manufacturing}

There are a number of indicators for sustainability, which include indicators based on environmental stewardship, economic growth, social well-being, technological advancement and performance management [18]. Researchers have been working to define and use indicators for sustainable manufacturing. Such research efforts to use indicators for sustainable manufacturing are maturing fast. In this section, we first discuss the earlier efforts, followed by a discussion on the presently acceptable and better recognized indicators for sustainable manufacturing.

\subsubsection{Earlier efforts}

Fan et al. [19] suggested that a comprehensive system is needed to implement sustainability indicators in manufacturing companies. They shortlisted a number of indicators used for sustainability measurement and attempted to evaluate those based on the criteria of relevance, analytical soundness and measurability. Shaw and Joung [20] proposed a sustainable manufacturing measurement infrastructure. They define sustainability measurement process as a sequence of operations, with the necessary instruments and tools and having the objective of determining the value of an indicator. Laurent et al. [21] investigated the ability of $\mathrm{CO}_{2}$ emissions (or carbon footprint) as a performance indicator for product or production activities. Their focus was to find out if there is any correlation between the Carbon Foot Print (CFP) and other types of environmental impacts like Human Toxicity Impacts (HTI). The overall environmental impact was investigated based on life-cycle assessment of several materials of major importance to manufacturing viz. metals and plastics.

In addition to the earlier efforts, there have been efforts by multiple organizations to define and adopt sustainable manufacturing indicators. An effort by the National Institute of Standards and Technology (NIST) is the Sustainable Manufacturing Indicator Repository (SMIR) [22], which defines indicators for sustainable manufacturing and addresses a range of sustainability issues. From an extensive review of publicly available indicator sets, the SMIR is based on five dimensions of sustainability: environmental stewardship, economic growth, social well-being, technological advancement, and performance management. 
Most recently, the Organization of Economic Co-operation and Development (OECD) has published a Sustainable Manufacturing Toolkit [23] which defines 18 indicators for sustainable manufacturing in three categories; namely inputs, operations and products. The input indicators are nonrenewable material intensity, restricted substances material intensity, and recycled-reused contents. The indicators for operations, eight in number, are water intensity, energy intensity, renewable proportion of energy, greenhouse gas intensity, residual gas, air release intensity, water release intensity, and proportion of natural land. Besides these, there are seven indicators for products, namely recycled/reused content, recyclability, renewable material content, non-renewable material intensity, restricted substances content, energy computation and greenhouse gas emissions intensity.

We identified that some indicators do affect performance of the other indicators. For example, the energy intensity effects other indicators like greenhouse gas intensity or renewable proportion of energy. In the following section, we discuss key indicators, which are important in the sense that these can help to improve manufacturing from the sustainability point of view. Manufacturing industries use these indicators when reporting sustainability [24].

\subsubsection{Key sustainable manufacturing indicators}

\section{a. Energy indicator}

Conserving and using energy optimally is crucial in manufacturing. Within the facility, energy conservation can be improved by monitoring the manufacturing process and corresponding equipment where losses occur due to escaped heat, standby mode, etc. We use the Organization for Economic Cooperation and Development [4] indicators for demonstration purposes.

According to OECD, any energy production, whether non-renewable or renewable, depletes nonrenewable resources (including habitats, fossil fuels and uranium), generates GHG (greenhouse gases) or both. Energy intensity (EI) in Mega Joule (MJ) is calculated by using Eq. 1 for production processes and overheads. The OECD suggests the energy intensity of the inputs can be included by extending the accounting boundary.

$$
E I=\frac{(\text { Energy consumed in production processes }+ \text { Energy consumend in overhead })}{\text { Normalization factor }}
$$

Depending on the production process, energy computations will have to be made. Also, depending on the production process there may be multiple methods to calculate energy consumed. For example, if we consider material removal by machining processes, energy can be computed based on the material removed during the process (removed volume) and the specific energy of the material. The amount of energy can also be computed for a direct energy meter reading. We must note here that there will be uncertainties and heuristics associated with the type of energy computation methodology and hence it is important to consider this when we characterize manufacturing processes to handle such uncertainties. We discuss sustainability characterization methodology in Section 4.

\section{b. Carbon dioxide}

Carbon dioxide emission calculations are dependent on the electricity generation based on the figures from the EPA's eGRID emission factors. According to the EPA, on an average, electricity sources emit $0.5925 \mathrm{~kg}$ of $\mathrm{CO}_{2}$ per $\mathrm{kWh}$. $\mathrm{CO}_{2}$ emissions for a particular state per $\mathrm{kWh}$ may vary greatly in accordance with the amount of clean energy in the energy supply. For example for Maryland, $\mathrm{CO}_{2}$ emissions are $0.608 \mathrm{~kg} / \mathrm{kWh}(1,337.6 \mathrm{lb} / \mathrm{MWh})$ while for the District of Colombia it is $1.2644 \mathrm{~kg} / \mathrm{kWh}(2,781.7$ $\mathrm{lb} / \mathrm{MWh}$ ) [25]. This indicator represents the GHG intensity of the facility including production processes, and overhead (energy-related emissions and business travel). The GHG (greenhouse gas) emissions associated with the production of input materials and the logistics (shipping of inputs and finished products as well as staff commuting) can also be counted by extending the accounting boundary, and has 
been included in Eq. 2. The Organization of Economic Co-operation and Development (OECD) states that the GHG intensity of a product use stage must be calculated separately and is not included here.

$$
G H G \text { Intensity }=\frac{\left(\begin{array}{c}
G H G \text { s released in energy consumption for production }+ \\
\text { GHGs released in energy consumption for overhead }+ \\
\text { GHGs released by transport used for business travel+ } \\
\text { Additional GHGs released from production process }
\end{array}\right)}{\text { Normalization factor }}
$$

Unit of the indicator: $\mathrm{tCO}_{2}$ equivalent/normalization factor

c. Waste

Waste minimization involves efforts to minimize resource and energy use during manufacture. For the same commercial output, usually the fewer materials are used, the less waste is produced. Waste minimization usually requires knowledge of the production process, cradle-to-grave analysis (the tracking of materials from their extraction to their return to earth) and detailed knowledge of the composition of the waste.

\section{d. Water}

Depending on the production process, water is often consumed for cooling, heating or washing. When water is consumed, such as when it is incorporated into beverages, it cannot easily be substituted or reduced. For that reason, the OECD indicator calculates only the intensity of total water intake of the overhead and production process. Equation 3 is used for determining water intensity.

$$
W I=\frac{(\text { Total water intake })}{\text { Normalization factor }}
$$

\section{e. Emissions}

It is important for the facility to also track releases of its individual air pollutants of concern, e.g., $\mathrm{NO}_{\mathrm{x}}$, $\mathrm{SO}_{\mathrm{x}}$, persistent organic pollutants (POPs), volatile organic compounds (VOCs), hazardous air pollutants, particulate matter, and/or other pollutants that are priorities for the state, region, locality, and public interest groups. These may be pollutants that are regulated or permitted. The facility should be able to identify which air pollutants to prioritize, and confirm this list with its community, regional or state officials.

The emission indicator represents the intensity of the weight of all releases to air during the reference year. Although it might be difficult or insignificant to track, the OECD recommends tracking the releases to air from overhead as well as production processes. Equation 4 provides a mathematical definition for air emissions.

$$
\text { Intensity of pollutant releases to air }=\frac{(\text { Weight of releases to air })}{\text { Normalisation } \text { factor }}
$$

Units are ton/normalization factor.

Table 2 presents a sample sustainability report. Depending on the industry and the sector, manufacturing key performance indicators are to be reported. The overall problem is the underlying measurement science and procedures in place to measure and report sustainability. Manufacturing industries lack the measurement science and the needed information base to measure and effectively compare environmental performance of manufacturing processes, resources and associated services with respect to sustainability. Moreover, there are no formal methods for acquiring and exchanging information for sustainability in manufacturing. The next section presents a review of the manufacturing process models. 
Table 2 Sample Sustainability Report

\begin{tabular}{|l|l|l|l|l|}
\hline SUSTAINABILITY REPORT & Year & \multicolumn{3}{|l|}{} \\
\hline Absolute Emissions & FY09 & FY10 & FY11 & FY12 \\
\hline Total energy usage $(\mathrm{MWh})$ & & & & \\
\hline Total gas \& oil $(\mathrm{MWh})$ & & & & \\
\hline Total electricity $(\mathrm{MWh})$ & & & & \\
\hline Total $\mathrm{CO}_{2}$ (ton) & & & & \\
\hline Total water usage $\left(1000 \mathrm{~m}^{3}\right)$ & & & & \\
\hline Total discharged water $\left(1000 \mathrm{~m}^{3}\right)$ & & & & \\
\hline Total VOC emissions (ton) & & & & \\
\hline Total waste-at-cost (ton) & & & & \\
\hline Total waste-to-landfill (ton) & & & & \\
\hline $\begin{array}{l}\text { Total European production volumes } \\
\text { (vehicles) }\end{array}$ & & & & \\
\hline Number of plants covered by result & & & & \\
\hline
\end{tabular}

\subsection{Manufacturing Process Models}

To understand the sustainability performance of manufacturing processes, engineers will need welldefined manufacturing process models. The sustainability performance is broadly dependent on all information related to manufacturing processes namely resource, tooling, material, and energy. A manufacturing process model must define relationships between sustainability performance and information related to manufacturing processes. Previous manufacturing process models mainly focused on what information is related to manufacturing processes yet do not explicitly show how manufacturing process information is related to the sustainability performance.

Subsequent sections provide an analysis and discussion of the previous manufacturing process models to identify the needed relationships between manufacturing process information and sustainability performance.

\subsubsection{Classification of process models}

Process models can be classified into language level and the model level according to information abstraction levels. Examples of general modeling languages include XML (Extensible Markup Language), UML (Unified Modeling Language), EXPRESS, KIF (Knowledge Interchange Format) and OWL (Ontology Web Language). At the language level, a process model defines fundamental entities and their relationship. IDEF0 (Integration Definition for Function Modeling) [26], BPMN (Business Process Modeling Notation) [27], and PSL (Process Specification Language) [28] are examples of process models at the language level. Engineers can use process modeling languages to build process models.

Process models in the model level can either be activity models or information models. Activity models describe data flow and precedence of manufacturing processes. The Systems Integration for Manufacturing Applications (SIMA) reference architecture - part 1 [29] defines reference activity models for product development. The SIMA activity model comprehensively explains processes and data flow (i.e. inputs, outputs, reference, and control flows) in product development using the IDEF0. Information models of manufacturing processes define entities and their relationships. The data flow in activity models can be entities in information models.

Information models of manufacturing processes can be further classified into the class level, and the property level. Information models in the class level focus on classes and their relationships to 
represent information related to manufacturing processes. A class diagram in the core manufacturing simulation data (CMSD) [30] can be one of information models in the class level. Information models in the property level define mathematical models of properties of classes related to manufacturing processes. Thiriez [31] analyzed the injection modeling process and provided an information model of the injection modeling process. The information model shows how properties of material, mold, machine, and process contribute to total energy use in an injection modeling process. The $\mathrm{CO}_{2} \mathrm{PE}$ ! project [14] is also developing manufacturing process models at the property level to provide reference models of life cycle inventory (LCI) data of manufacturing processes.

Table 3 shows the process model classification. Following sub-sections specifically provide an analysis of process modeling languages, process activity models, and process information models.

Table 3 Process model classification

\begin{tabular}{c|l|l}
\hline \multirow{4}{*}{$\begin{array}{c}\text { Modeling } \\
\text { languages }\end{array}$} & $\begin{array}{l}\text { General modeling } \\
\text { languages }\end{array}$ & $\begin{array}{l}\text { XML, } \\
\text { UML, EXPRESS, } \\
\text { KIF, OWL }\end{array}$ \\
\cline { 2 - 3 } $\begin{array}{l}\text { Process-specific } \\
\text { modeling languages } \\
\text { process models }\end{array}$ & $\begin{array}{l}\text { IDEF0, } \\
\text { BPMN, } \\
\text { PSL }\end{array}$ \\
\cline { 2 - 3 } & $\begin{array}{l}\text { Activity models } \\
\text { Information models }\end{array}$ & $\begin{array}{l}\text { SIMA reference architecture - Part1 } \\
\text { ISO 15531-1 Manufacturing management data } \\
\text { (Claxchange (MANDATE) }\end{array}$ \\
\cline { 2 - 3 } & $\begin{array}{l}\text { Information models } \\
\text { (Property level) }\end{array}$ & $\begin{array}{l}\text { Injection modeling process analysis } \\
\text { CO2PE - unit manufacturing process analysis }\end{array}$ \\
\hline
\end{tabular}

\subsubsection{Process modeling languages}

Process modeling languages have common process modeling elements such as process input, and output, and the relationship among them. The IDEF0, BPMN, and PSL are typical process modeling languages. Each process modeling language also defines further specialized elements for their own purpose. For example, the BPMN classifies processes into "Task" and "Sub process," and the "Task" element is further classified into "Abstract Task," "Service Task," "Send Task," "Receive Task," and so on. Although IDEF0 does not have such specialized processes, it classifies inputs and outputs into four types of data flow: inputs, outputs, controls, and mechanisms. PSL is defined in a logical language so that it can define logical relationships among activities to represent complex order of precedence and preconditions of processes.

Note that capturing relationships between manufacturing information and sustainability performance does not need all of the process modeling elements. The following modeling elements are considered as necessary and sufficient elements for unit manufacturing process information modeling.

- Unit manufacturing processes and operations

- Inputs and outputs

- Operation rules (conditions and restrictions)

- Operation resources

- Dataflow among operations 
A unit manufacturing process is a top-level process when developing information models. Individual operations within the unit manufacturing process can be considered as sub-levels. For example, if an injection molding is a unit manufacturing process, its operations can be: filling plastic pellets, clamping a mold, screwing and melting plastic, injecting plastic, cooling a mold, and ejecting a part. Each operation requires inputs (i.e., energy and materials) and operation resources (i.e., machines, computers, or human) to make outputs (i.e., energy loss, melted plastics, parts). Operation rules control inputs, outputs, and operation resources. Dataflow among operations represent inputs and output flow among operations. Considering the necessary modeling elements in the unit manufacturing process, the IDEF0 or UML can be selected to represent data flow in a unit manufacturing process.

\subsubsection{Manufacturing process - activity models}

The SIMA (Systems Integration for Manufacturing Applications) activity model is a reference process model for product realization. The SIMA activity model is described in IDEF0. The top process in the SIMA activity model is "A0: Realize Product," and it has four sub-processes: “A1: Design Product," “A2: Engineer Manufacture of Product," “A3: Engineer Production System,” and "A4: Produce Product.” The SIMA activity model defines further detail sub-processes as well as inputs, outputs, controls, and mechanisms of sub-processes.

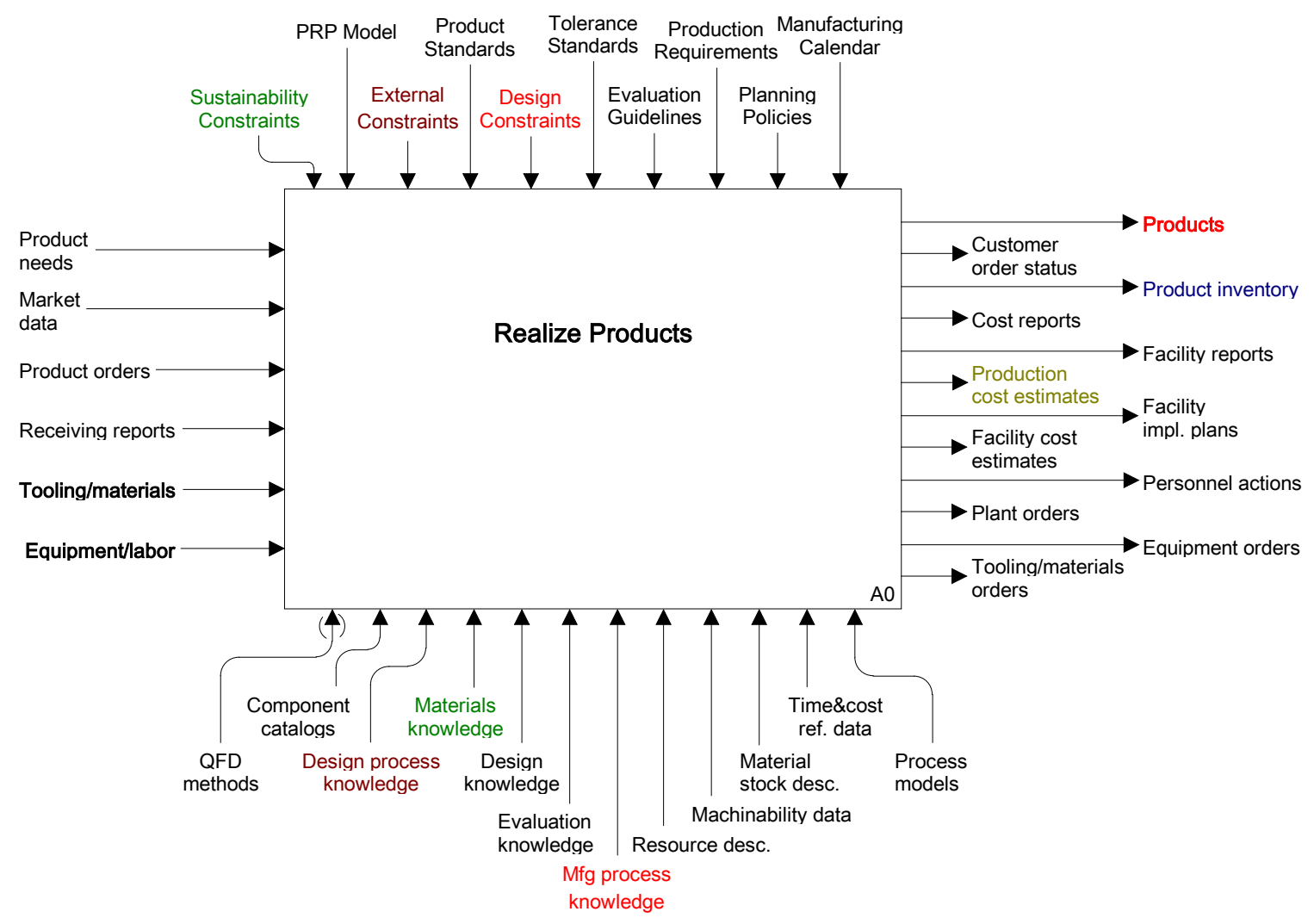

Figure 3 SIMA A0: Realize product activity diagram

The SIMA activity model defines activities where "process model” information is used. One of the activities using "process model” information is the "A213: Select Processes" activity. Figure 4 shows the activity in IDEF0. 


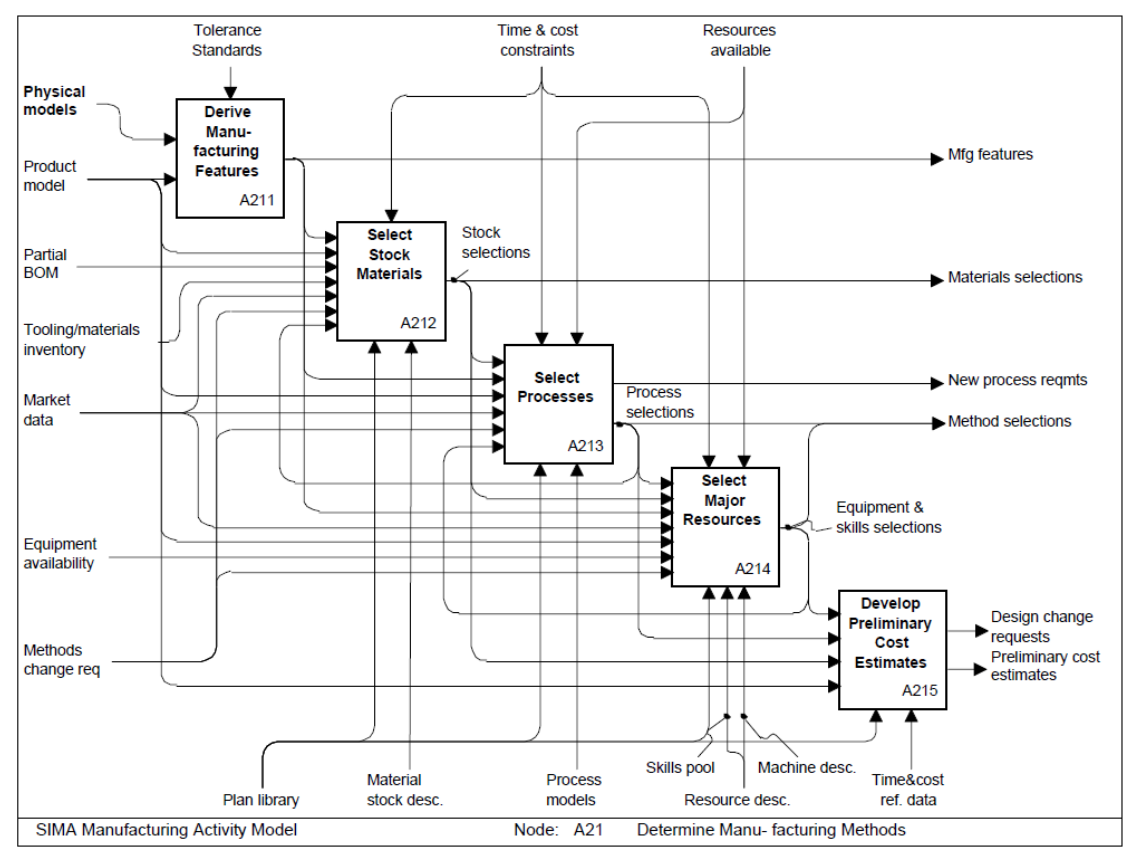

Figure 4 A21: Determine manufacturing methods activity in the SIMA model activity.

According to the SIMA model, engineers do the following tasks in the “A213: Select Processes”

- Choose the major processes that transform material stocks into the final product, including fabrication and assembly processes

- Associate the processes with design or manufacturing features and the related datums and tolerances

- Develop the inspection plan

- Determine what features are to be measured or otherwise inspected and what the qualifying criteria are

In the A213 activity, engineers make a decision on selecting manufacturing processes to realize a product model. Product models, bill of material (BOM), market data, equipment, and material information are inputs for the decision. Process models are references for the decision. The inputs can be changed if a new product model is introduced, but the references are not. Engineers select the best manufacturing process that satisfies time, cost, and resource constraints. Sustainability performance of manufacturing processes can be introduced as a new constraint for the process selection activity [32].

\subsubsection{Manufacturing process - information models}

Some manufacturing process standards define information models including manufacturing process class definitions and its relationships to other classes. The CMSD standard for example, defines a manufacturing process class as shown in Figure 5. The process class in the CMSD defines what information is necessary for process planning and simulation. The process class has attributes, which are related to other classes, such as produced part, consumed part, required resources, machine program, setup and operation time, cost, and material information. 


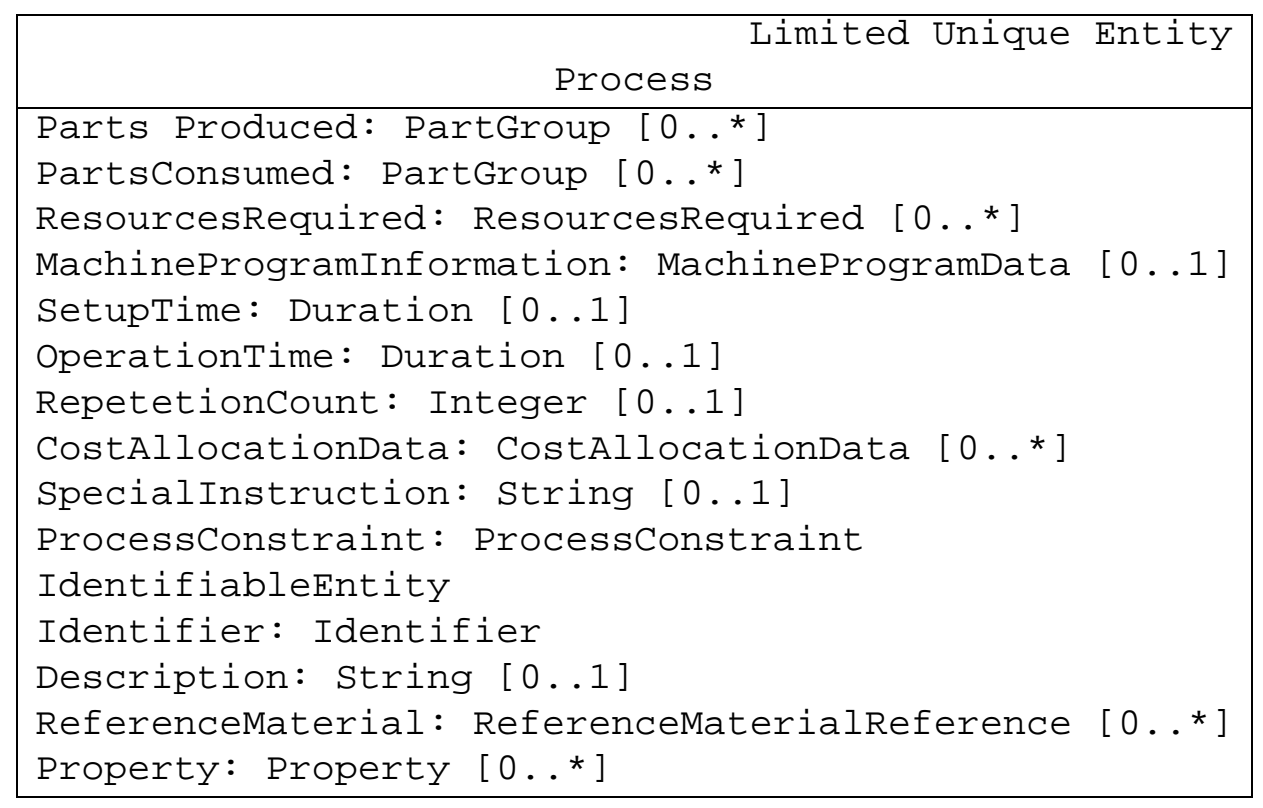

Figure 5 Process class defined in the CMSD

Although a process class shows what information is related to manufacturing processes, it does not tell how the information influences the performance of manufacturing processes. Thiriez [31, 33] analyzed an injection molding process and developed a process model with property level detail. The process model explains how to calculate the amount of necessary energy to produce a kilogram part using an injection molding process with given material types and mold shape. An injection modeling process consists of several operations, so the total necessary energy of an injection molding is a sum of necessary energy for those operations.

The following equations from reference [31] show two energy models: ( $E_{\text {Melt }}$ [Eq. 5 and 6] to melt polymers, and ( $\left.E_{F i l l}\right)$ [Eq.7] to fill a mold with melted polymers. These equations show how properties of material and part geometry affect the amount of necessary energy for an injection modeling process.

For non-crystalline polymers: $\quad E_{\text {melt }}=m C_{p}\left(T_{2}-T_{1}\right)$

For crystalline polymers: $\quad E_{\text {melt }}=m C_{p}\left(T_{2}-T_{1}\right)+\lambda m H_{F}$

Where, $\mathrm{m}$ is the mass

$\mathrm{C}_{\mathrm{p}}$ is the specific heat capacity of the polymer

$\mathrm{T}_{2}$ and $\mathrm{T}_{1}$ are the initial temperature and the temperature of the injected polymer

$\lambda$ is the degree of crystallization, which is a property of material

$\mathrm{H}_{\mathrm{F}}$ is the heat of fusion for $100 \%$ crystalline polymer

Filling energy

$$
E_{f i l l}=\frac{2^{\left(\frac{1}{S}+1\right)} 3^{\left(\frac{1}{s}\right)} \eta_{0} e^{-\zeta\left(T-T_{0}\right)} Q^{\frac{1}{S}} L^{2} W^{\left(1-\frac{1}{s}\right)}}{t^{\left(\frac{2}{s}\right)}}
$$

Where, $\eta_{0}$ belongs to $\eta=\eta_{0} \gamma^{\frac{1}{s}-1} e^{-\zeta\left(T-T_{0}\right)}$

$\eta$ is the viscosity of the polymer

$\gamma$ is the shear rate

$W$ is the width of the plate, and

$L$ is the length of the plate. 
One of the goals of the CO2PE! effort is to develop a methodology that allows providing manufacturing processes related data in a format useful for inclusion in LCI databases. The effort includes developing the unit manufacturing process model at the property level. Besides, there are standards like the ISO 14048: Environmental management-Life cycle assessment-Data documentation format [34] and commercial data formats like the [35] and [36] for the LCI data. The objective was to define data formats to exchange LCI data among life cycle assessment (LCA) tools. These data formats are useful to know what performance of manufacturing processes needs to be captured in a process model, but they do not explicitly explain what information influences the performance of manufacturing processes in the property level detail.

Having reviewed the previous manufacturing process models in various abstraction levels, it is clear that one generic process model cannot satisfy different usages of the process model. However, we believe that reference process models represented as a function between inputs and performance indicators in the process selection activity can be very useful (see Figure 6). The function does not tell how to calculate performance indicators of a manufacturing process with given inputs. If an individual unit manufacturing process had its own process model in property level detail, the process model can be used as a reference for process selection activities.

\begin{tabular}{|ll|}
\hline & \multicolumn{1}{c|}{$\quad C=f(P, F, K, M, E)$} \\
$C$ & $\quad \begin{array}{l}\text { : performance indicators of manufacturing processes } \\
\text { (i.e. throughput, cost, energy and material use, etc.) }\end{array}$ \\
$f$ & : reference manufacturing model function \\
$P$ & : product models including bills-of-materials, geometry, and tolerance \\
$D$ & : demand \\
$M$ & : selected material information. \\
$R$ & : resources including machines and tools \\
\hline
\end{tabular}

Figure 6 Function between manufacturing process information and performance

In addition to developing information models, it is important to consider the portability and robustness of such information models to implement solutions to support sustainable manufacturing. The next section reviews selected software tools that support sustainability analysis.

\subsection{Software Tools}

The software tools used for determining sustainability help reduce the time taken for sustainability assessment. The tools generally rely on different LCI databases. From the review of the various environmental assessment software tools (Table 4), it was observed that measurement of impact assessment for a product was based on the LCI database provided by different organizations. The major deficiency in these LCI databases is that, details up to the level of individual manufacturing processes are not included. These databases provide LCI information, which is based on the BOM. Furthermore, the information is region specific and the scientific basis of the LCI is unknown. For example, although LCI information is available for cast or rolled steel process, there is no information related to the numerous operations being performed on the sheet such as punching, blanking, shearing and bending. Presently available software tools, which depend on LCI databases, are therefore incomplete when it comes to performance measurement for sustainability. We evaluated several LCA-based software tools [8, 9, 29, 30-32] and found that manufacturing process-specific LCI is not available. 
Table 4 Summary of different software tools for sustainability assessment

\begin{tabular}{|c|c|c|c|}
\hline Software & Databases & $\begin{array}{c}\text { Impact Assessment } \\
\text { Methods }\end{array}$ & Major functions \\
\hline Software 1 & $\begin{array}{l}\text { USLCI, Ecoinvent, } \\
\text { GaBi database }\end{array}$ & $\begin{array}{l}\text { CML 96/2001/2007, } \\
\text { Ecoindicator 95/99, EDIP } \\
\text { 97/2003, TRACI, IO2+ } \\
\text { and others }\end{array}$ & $\begin{array}{l}\text { Impact } \\
\text { assessment }\end{array}$ \\
\hline Software 2 & $\begin{array}{l}\text { Ecoinvent, USLCI, } \\
\text { ELCD, US Input- } \\
\text { Output, EU \& Danish } \\
\text { Input \& Output, Dutch } \\
\text { Input -Output, LCA } \\
\text { Food, Industry Data, } \\
\text { IVAM, Japanese } \\
\text { input-output }\end{array}$ & $\begin{array}{l}\text { ReCiPe, Eco-indicator } \\
\text { 99, USEtox, IPCC 2007, } \\
\text { EPD, Impact 2002+, } \\
\text { CML-IA, Traci 2, BEES, } \\
\text { Ecological Footprint } \\
\text { EDIP 2003, Ecological } \\
\text { scarcity 2006, EPS 2000, } \\
\text { Greenhouse }\end{array}$ & $\begin{array}{l}\text { Impact } \\
\text { assessment }\end{array}$ \\
\hline Software 3 & No separate database & $\begin{array}{l}\text { Waste from Electronic } \\
\text { and Electrical Equipment } \\
\text { (WEEE) Restriction of } \\
\text { Hazardous Substances } \\
\text { (RoHS) }\end{array}$ & $\begin{array}{l}\text { Impact } \\
\text { assessment during } \\
\text { conceptual stage } \\
\text { of design }\end{array}$ \\
\hline Software 4 & $\begin{array}{l}\text { Cloud hosted Material } \\
\text { Universe - }\end{array}$ & $\begin{array}{l}\mathrm{CO}_{2} \text { footprint, energy } \\
\text { usage, water usage, and } \\
\text { RoHS }\end{array}$ & $\begin{array}{l}\text { Selection of } \\
\text { environmental } \\
\text { compliance } \\
\text { material } \\
\end{array}$ \\
\hline $\begin{array}{l}\text { Other PLM } \\
\text { Tools }\end{array}$ & $\begin{array}{l}\text { Integrate with internal } \\
\text { database of the } \\
\text { company }\end{array}$ & $\begin{array}{l}\mathrm{CO}_{2} \text { footprint, energy } \\
\text { usage }\end{array}$ & $\begin{array}{l}\text { Environmental } \\
\text { impact of design } \\
\text { alternatives } \\
\end{array}$ \\
\hline
\end{tabular}

\section{Methodology Development}

Manufacturing industries need a systems approach to realize sustainability across the enterprise, bridge the information gap and deliver business growth [41]. From the above sections it is clear that research and development of solution enabling measurement science, methodologies for knowledge management and sustainability assessment technologies are crucial to ensure sustainability in manufacturing.

Manufacturing industries are challenged to remain globally competitive, improve productivity, and reduce environmental impacts and energy requirements. These changes require a transformation from manufacturing practices based on human experience towards scientific-based modeling, decision making, and production. This requires the development of fundamental measurements, standards, and knowledge base to enable U.S. manufacturers to make this transformation. The US manufacturing industry currently lacks the measurement science to measure and effectively compare the performance of unit manufacturing processes with respect to sustainability.

Besides lack of measurement science, manufacturing industries also lack the needed information base to measure and effectively compare environmental performance of manufacturing processes, resources and services with respect to sustainability. Current use of ad-hoc methods to informally describe sustainability of manufacturing processes results in inaccurate and ambiguous comparisons of these processes. Furthermore, there are no formal methods for acquiring and exchanging information that help establish a consolidated sustainability information base. Information management is crucial for sustainable manufacturing through a consolidated information base about the manufacturing processes, facilities and impact and accessible information models. 
The subsequent section introduces a sustainability characterization methodology that bridges the measurement science and manufacturing knowledge management for sustainable manufacturing.

\subsection{Sustainability Characterization Methodology}

The new technical idea is the sustainability characterization through unit manufacturing processes for performance modeling and assessment of manufacturing systems. Sustainability characterization will create the information crucial in the decision making related to sustainability. Such information includes, but not limited to energy, emissions, pollutants, waste and scrap, alternative materials, cycle times and productivity. A set of common computable metrics (carbon emissions, material waste, toxicity, etc.) as discussed in Section 3.2.2 will be identified that use the sustainability characterized information for decisions comparing within and across manufacturing processes for carbon foot printing, energy auditing besides others.

The lack of measurement science will be addressed by developing a science-based assessment methodology and structured information, based on the fundamental sustainability characterization of unit manufacturing processes (UMP). UMPs are those individual operations (e.g., casting, machining, and surface treatment) that transform raw material and add value to the work piece as it becomes a final product. The measurement science activities for sustainability characterization methodology will comprise of (1) definitions of key performance indicators and common computable sustainability metrics; (2) formal information model that defines the analytics for computing the manufacturing process sustainability; and (3) manufacturing process-specific data sets that instantiate the information models and enables execution of computable metrics. Figure 8 illustrates the components of the sustainability characterization methodology. Such sustainability characterization will support the required evaluation of sustainability performance by allowing science-based rigorous assessment of manufacturing processes.

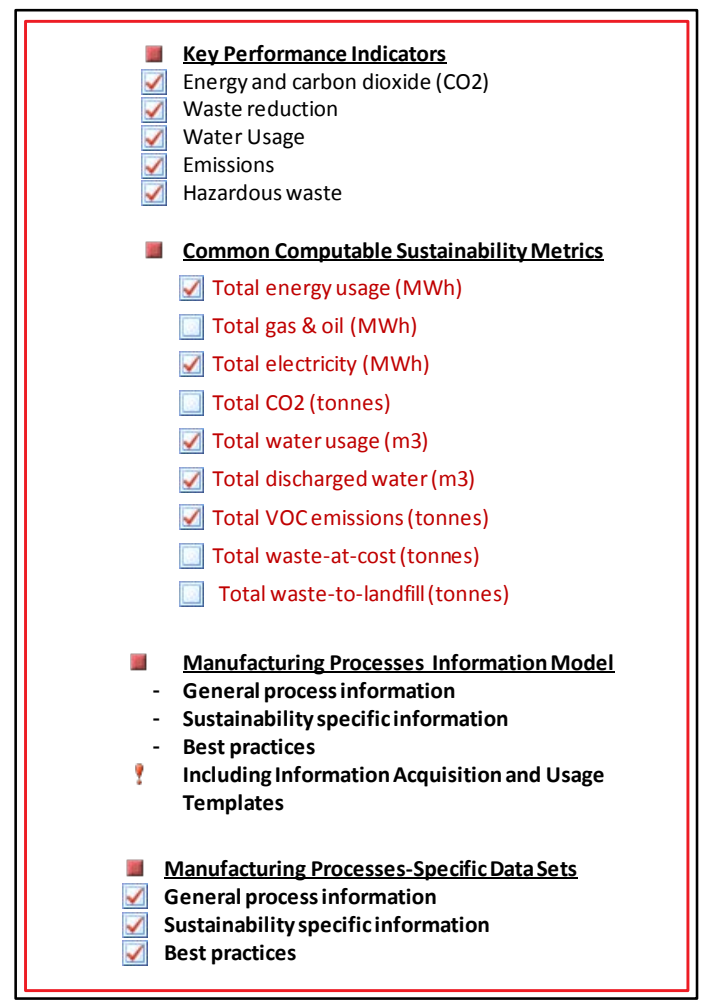


Figure 8 Sustainability characterization components

To illustrate the usefulness of sustainability characterization, Figures 9 and 10 provide the logical model and an example using the injection molding process respectively. One of the challenges is to extract the key information of manufacturing processes from all the relevant data available in the form of text documents, handbooks, catalogs, etc. Relevant work on the unit process life cycle inventory (uplci) is pursued at the Wichita State University. Their uplci profile is for a high production manufacturing operation, defined as the use of processes that generally have high automation and are in the medium to high throughput production compared to all other machines/equipment that perform a similar operation.

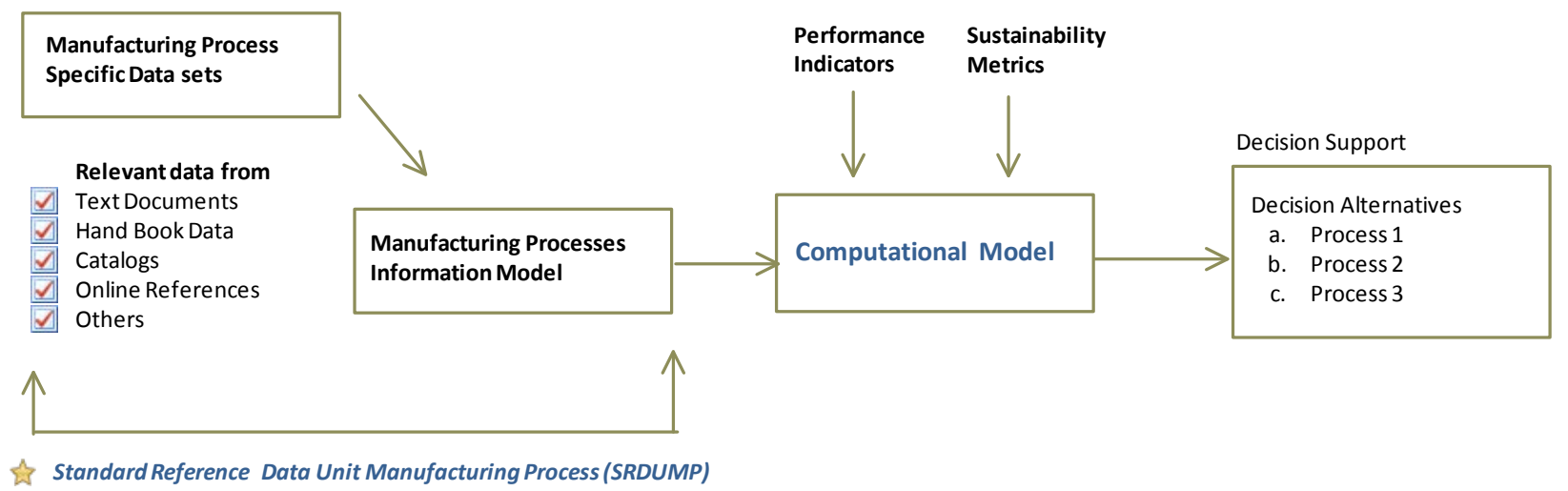

Figure 9 Logical model for sustainability characterization

As mentioned in Section 3.3.4, a major challenge is to represent the key information as unit manufacturing information model, capable of providing the computing functionality for sustainability to provide the necessary decision support. Note that this effort can facilitate the development of a structured information base by making available a Standard Reference Data for Unit Manufacturing Process (SRDUMP) consistent with NIST's Standard Reference Materials (SRM) [42], and Standard Reference Data (SRD) [43] efforts.

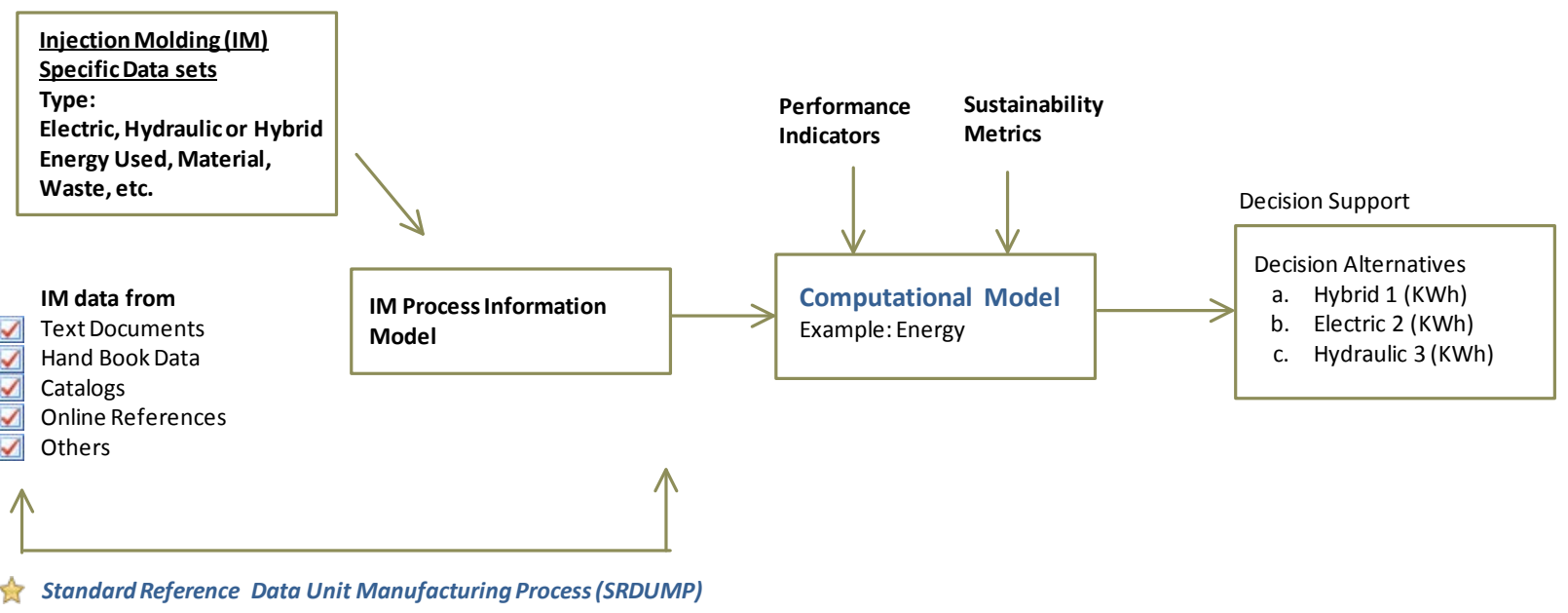


Figure 10 Logical model demonstrating sustainability characterization

\section{Conclusions}

This report is a preliminary review of the related and current developments on sustainability for manufacturing, with an emphasis on sustainability characterization to facilitate measurement science and methodology development to evaluate sustainability performance.

This report first presented how process characterization is an inherent part of performance measurement, highlighting the challenges in developing the measurement science for sustainability of manufacturing processes. We briefly presented different manufacturing process classifications, sustainability indicators, and process information models followed by a brief review of the relevant software tools for sustainability.

To develop a science-based methodology for sustainability characterization, major tasks under this project are planned along four phases. Phase one involves the tasks related to the fundamental sustainability characterization. Research activities involve requirements gathering, sustainability characterization methodology development, and science-based measurement procedures and process data representation for UMPs. Phase two involves the tasks aligned with performance modeling of manufacturing processes using information generated through sustainability characterization. Research activities involve the development of sustainability focused manufacturing process analytical models to compute sustainability performance of the UMP. Phase three involves the tasks that lead to the standard on sustainability assessment methodology for identified processes and the SRDUMP and phase four involves the verification and validation of the methodology and standards created.

\section{Disclaimer}

Certain products or services are identified in the paper to foster understanding. Such identification does not imply recommendation or endorsement by the National Institute of Standards and Technology, nor does it imply that the products or services identified are necessarily the best available for the purpose.

\section{Bibliography}

[1] How does Commerce Define Sustainable Manufacturing?, International Trade Administration, US Department of Commerce, [Web page]: http://rade.gov/competitiveness/sustainablemanufacturing/how_doc_defines_SM.asp [accessed 12/1/12].

[2] The Facts About Modern Manufacturing, The Manufacturing Institute, [Web page]: http://www.themanufacturinginstitute.org/Research/Facts-About-Modern-Manufacturing/FactsAbout-Modern-Manufacturing.aspx. [accessed 12/12/12].

[3] Metalcasters alliance for government affairs, American Foundary Society (AFS), [Web page]: http://www.metalcastinggov.com/ClimChg.asp. [accessed 8/14/12].

[4] OECD Sustainable Manufacturing Indicators, The Organisation for Economic Co-operation and Development (OECD), OECD Better Policies for Better Lives, [Web page]:

http://www.oecd.org. [accessed 12/7/12].

[5] J. Jeswiet and S. Kara, Carbon emissions and CESTM in manufacturing, CIRP Annals Manufacturing Technology. vol. 57 (51), p. 17-20 (2008). 
[6] Lean Manufacturing and the Environment, United States Environmental Protection Agency (EPA), [Web page]: http://www.epa.gov/lean/environment/pdf/leanreport.pdf. [accessed 12/15/12].

[7] Engineering Statistics Handbook (e-version) available at URL:

http://www.itl.nist.gov/div898/handbook, National Institute of Standards and Technology, Gaithersburg, MD, USA (2003)

[8] Unit Manufacturing Processes: Issues and Opportunities in Research, The National Academic Press, Washington D.C, USA (1995)

[9] GaBi Databases, PE-International, [Web page]: http://www.gabi-

software.com/america/databases/gabi-databases/. [accessed 12/16/12].

[10] Full Service Tailored Your Needs, Product Ecology Consultants, [Web page]:

http://www.pre-sustainability.com/content/solutions. [accessed12/12/12].

[11] K. Kellens, W. Dewulf, M. Overcash, M. Z. Hauschild and J. R. Duflou, Methodology for systematic analysis and improvement of manufacturing unit process life-cycle inventory

(UPLCI)-CO2PE! initiative (cooperative effort on process emissions in manufacturing). Part 1: Methodology Description, International Journal of Life Cycle Assessment. vol. 17 (11), 69-78 (2011).

[12] R. H. Todd, K. Allen and L. Alting, Manufacturing Processes Reference Guide, Industrial Press Inc., New York, USA (1993)

[13] Manufacturing Processes - Terms and Definitions, NA 152 Fundamental Technical

Standards Committee, [Web page]: http://www.natg.din.de. [accessed 12/12/12].

[14] Cooperative Effort on Process Emissions in Manufacturing (CO2PE!), [Web page]:

http://www.mech.kuleuven.be/co2pe!/index.php. [accessed 12/12/12].

[15] M. F. Ashby, Materials selection in mechanical design, Butterworth-Hienemann, Oxford, UK (2005)

[16] Acquisition Community Connection, [Web page]: https://acc.dau.mil/adl/enUS/18282/file/691/MM\%20Taxonomy.ppt. [accessed 12/12/12].

[17] Manufacturing Knowledge Centre, MFG.COM, [Web page]: http://www.mfg.com. [accessed 7/23/12].

[18] S. C. Feng, Sustainable manufacturing indicators repository, in International Design Engineering Technical Conferences \& Computers and Information Science in Engineering, Washington D.C, USA (2011) Aug. 28-31.

[19] C. Fan, J. D. Carrell and H. C. Zhang, An Investigation of Indicators for Measuring Sustainable Manufacturing, in IEEE International Symposium on Sustainable Systems and Technology, Arlington, VA, USA (2010) May 17-19.

[20] S. C. Shaw and C. B. Joung, An Overview of a Proposed Measurement Infrastructure for Sustainable Manufacturing, in The 7th Global Conference on Sustainable Manufacturing, Chennai, India. Dec. 2-4 (2009)

[21] A. Laurent, S. I. Olsen and M. Z. Hauschild, Carbon footprint as environmental performance indicator for the manufacturing industry, CIRP Annals - Manufacturing Technology. vol. 59, p 37-40 (2010).

[22] Sustainable Manufacturing Indicators Repository, Engineering Laboratory, National Institute of Standards and Technology, [Web page]: http://www.mel.nist.gov/msid/SMIR/. [accessed 12/20/12]. 
[23] Sustainable Manufacturing Toolkit, Organization for Economic Co-operation and Development, France [Web page]: http://www.oecd.org/innovation/green/toolkit/. [accessed 12/12/12].

[24] Manufacturing, Toyota Motor Corporation, [Web page]:

http://www.toyota.eu/sustainability/environmental_performance/Pages/Manufacturing.aspx. [accessed 12/12/12].

[25] State-level eGRID emissions, US Environmental Protection Agency, USA [Web page]: http://www.epa.gov/cleanenergy/energy-resources/egrid/index.html. [accessed 12/15/12]. [26] B. Lightsey, Systems Engineering Fundamentals, Defence Acquisition University, Belvoir, VA (2001).

[27] Documents associated with business process model and notation BPMN v 2.0, OMG, [Web page]: http://www.omg.org/spec/BPMN/2.0/. [accessed 12/12/12].

[28] Process Specifications Language, National Institute of Standards and Technology, [Web page]: http://www.mel.nist.gov/psl/. [accessed 12/28/12].

[29] E. Barkmeyer, N. Christopher, S. C. Feng, J. Fowler, S. Frechette, J. Jones, K. Jurrens, C. McLean, M. Pratt, H. A. Scott, M. K. Senehi, R. Sriram and E. Wallace, SIMA Reference Architecture Part I: Activity Models, NISTIR 5939, National Institute of Standards and Technology, Gaithersburg, MD, USA (1997).

[30] F. H. Riddick and Y. T. Lee, Core Manufacturing Simulation Data (CMSD): A Standard Representation for Manufacturing Simulation-related Information, in Fall Simulation Interoperability Workshop (Fall SIW) SISO, (2010) Sept. 20-24.

[31] A. Thiriez, An environmental analysis of injection molding, Master's Thesis, Mechanical Engineering Department, Massachusets Institute of Technology, Providence (2006).

[32] M. Mani, B. J. Johansson, K. W. Lyons, R. D. Sriram and G. Ameta, Modeling, Simulation and Analysis for Sustainable Product Development, NISTIR 7745, National Institute of Standards and Technology, Gaithersburg, MD, USA (2010).

[33] A. Thiriez and T. Gutowski, An Environmental Analysis of Injection Molding, in IEEE International Symposium on Electronics and the Environment, San Francisco, CA (2006) May 811 .

[34] ISO/TS 14048:2002, International Standards Organization, Geneva, Switzerland (2002).

[35] Swiss Centre for Life Cycle Inventories, Ecoinvent Centre, [Web page]:

http://www.ecoinvent.org/database/ecospold-data-format/. [accessed 12/12/12].

[36] International Reference Life Cycle Data System (ILCD), European Commission - Joint

Research Centre - Institute for Environment and Sustainability, Ispra, Italy (2011).

[37] Design for Environment, DFMA, [Web page]: http://www.dfma.com/software/dfe.htm.

[accessed 12/2/12].

[38] Eco Material Advisor, Granta Materials, [Web page]:

http://www.grantadesign.com/news/news/2011/ema-sep2011.shtml. [accessed 12/2/12].

[39] Granta Materials Intelligence, Granta Materials, [Web page]:

http://www.grantadesign.com/products/mi/. [accessed 12/8/12].

[40] Windchill LCA, [Web page]: http://www.ptc.com/products/windchill/lca. [accessed $12 / 12 / 12]$.

[41] The Challenges Ahead for Supply Chains: McKinsey Global Survey Results McKinsey \& Company, McKinsey Quarterly, USA [Web page]: http://www.mckinseyquarterly.com. [accessed 12/11/12]. 
[42] About NIST Standard Reference Materials® (SRM), National Institute of Standards and Technology, [Web page]: http://www.nist.gov/srm/. [accessed 12/12/12].

[43] NIST Standard Reference Data, National Institute of Standards and Technology, [Web page]: http://www.nist.gov/srd/index.cfm. [accessed 12/12/12].

\section{Appendix}

\section{Manufacturing Management Taxonomy}

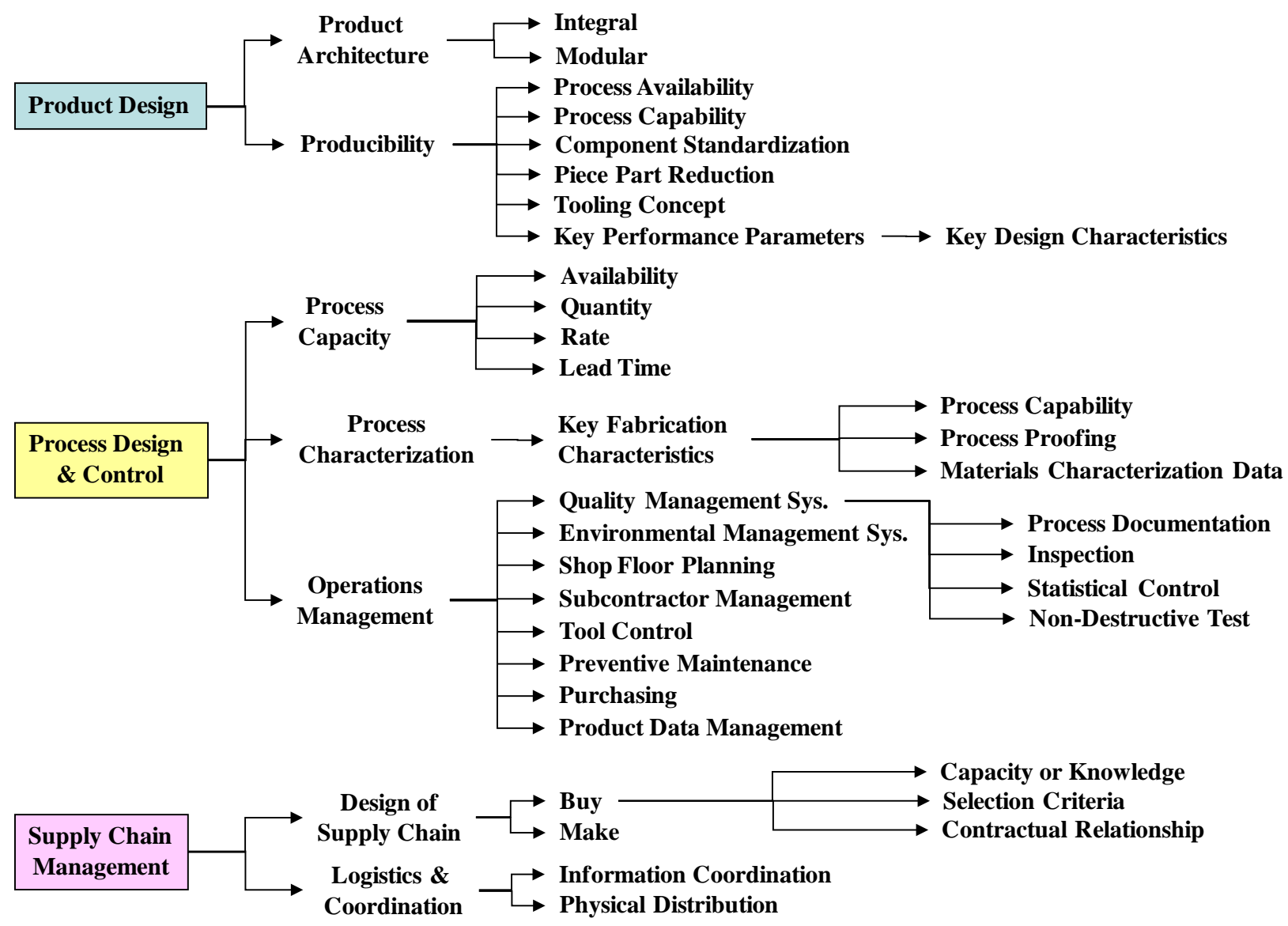

Figure A1: Manufacturing Management Taxonomy

\footnotetext{
${ }^{\mathrm{i}}$ Taxonomy is a documented and orderly set of types, classifications, categorizations and/or principles that are often achieved through mechanisms including but not limited to naming, defining and/or the grouping of attributes, and which ultimately help to describe, differentiate, identify, arrange and provide contextual relationships between Manufacturing Items, Entities or Types.
} 